\title{
SIMULATION STUDY ON THE BLOCKING EFFECT AND VIBRATION REDUCTION CHARACTERISTICS OF ACOUSTIC BLACK HOLE IN THIN PLATE
}

CLiu Z., ORCID: 0000-0002-7603-1060, Ogarev Mordovia State University, Jiangsu University of Science and Technology, Zhenjiang, China, liu_zuncheng@163.com

(CZhou Y., ORCID: 0000-0002-4530-5137, Ogarev Mordovia State University, Jiangsu University of Science and Technology, Zhenjiang, China, 1328832703@qq.com

@Golyanin A., Ogarev Mordovia State University, Saransk, Russia, Anton.golyanin@yandex.ru

\section{ИМИТАЦИОННОЕ ИССЛЕДОВАНИЕ ЭФФЕКТА БЛОКИРОВАНИЯ И СНИЖЕНИЯ ВИБРАЦИИ АКУСТИЧЕСКОЙ ЧЕРНОЙ ДЫРЫ В ТОНКОЙ ПЛАСТИНЕ}

(СЛю Ц., ORCID: 0000-0002-7603-1060, Национальный исследовательский Мордовский государственный университет им. Н. П. Огарева, Цзянсуский университет науки и техники, 2. Чжээнизян, Китай, liu_zuncheng@163.com

(C)жжоу И., ORCID: 0000-0002-4530-5137, Национальный исследовательский Мордовский государственный университет им. Н. П. Огарева, Цзянсуский университет науки и техники, 2. Чжэньизян, Китай, 1328832703@qq.com

(СГолянин А., Наџиональный исследовательский Мордовский государственный университет им. Н. П. Огарева, г. Саранск, Россия, Anton.golyanin@yandex.ru

Abstract. Recently, more and more scholars have devoted themselves to researching new methods of vibration reduction and noise reduction by manipulating the elastic waves in the structure to achieve the purpose of vibration reduction and noise reduction. To this end, a new type of 'acoustic black hole' structure is proposed, which reduces structural vibration while avoiding problems such as mass increase. In this paper, the vibration damping performance of the structure is mainly calculated by finite element software, and the energy concentration effect of the thin plate containing the acoustic black hole is verified by finite element analysis. A thin plate structure with four acoustic black holes is proposed. The calculation shows that the structure has obvious vibration reduction effect, and the vibration reduction effect can reach more than $20 \mathrm{~dB}$ at high frequency.

Аннотация. В последнее время все больше ученых посвящают себя исследованию новых методов снижения вибрации и шума путем манипулирования упругими волнами, для достижения цели снижения вибрации и шума. С этой целью предлагается новый тип структуры «акустической черной дыры», которая уменьшает вибрацию, избегая при этом таких проблем, как увеличение массы. В настоящей работе эффективность демпфирования колебаний конструкции в основном вычисляется с помощью программного обеспечения конечных элементов, а эффект концентрации энергии тонкой пластины, содержащей акустическую черную дыру, проверяется методом конечных элементов. Предложена тонкая пластинчатая структура с четырьмя акустическими черными дырами. Расчет показывает, что структура имеет очевидный эффект снижения вибрации, и эффект снижения вибрации может достигать более 20 дБ на высокой частоте. 
Keywords: acoustic black hole, thin plate, vibration damping, time domain, frequency domain, mechanical energy flow.

Ключевые слова: акустическая черная дыра, тонкая пластина, демпфирование колебаний, временная область, частотная область, поток механической энергии.

\section{Research Background and Theoretical Research}

Acoustic black hole ( $\mathrm{ABH})$ structure, as a new type of physical object, has been gradually explored and developed in the past ten years. It introduces the concept of black hole in astrophysics into the field of wave and acoustic vibration, and proposes and studies it as a completely new concept. C. L. Pekeris [1] in his book The Theory of Sound Propagation in a Variable-Speed Half-Space studied the characteristics of sound waves propagating in a layered ocean, and the sound velocity profile linearly decreased to zero with depth. There is a similar black hole effect in acoustics. It shows that in a specific non-uniform layered medium, the wave velocity of the sound wave will change with the thickness of the medium. When the thickness of the medium decreases, the wave velocity of the sound wave will gradually decrease to zero so that no wave reflection occurs.

Subsequently, in 1988, M. A. Mironov [2] also found a similar phenomenon and predicted the possibility of zero reflection in an ideal quadratic wedge-shaped bending wave. In a thin-plate wedgeshaped structure, when the thickness of the thin plate and the medium distance $\mathrm{x}$ are related by the power law $\mathrm{h}$ (When the change of $\mathrm{x}$ ) $=\varepsilon \cdot \mathrm{x}^{\mathrm{m}}$ decreases, the wave velocity of the bending wave will gradually decrease as the thickness of the thin plate decreases. In the case of an ideal quadratic wedge, the wave velocity can be reduced to zero, which means that the bending wave is stagnant and the wave is realized. Zero reflection.

V. V. Krylov has used the geometric acoustic approximation method to analyze the propagation of bending waves in solid wedges since 1989 [3]. In 2001, the zero-reflection effect of sound waves in thin plates with variable thickness was used as an effective absorber of bending vibration [4], in 2004 the physical effect was named "acoustic black hole" [5]. Theoretical research shows that an ideal acoustic black hole structure can perfectly capture waves using its zero-reflection effect to form a trap, but it is limited by processing and manufacturing processes. Ideal acoustics The black hole structure is difficult to achieve in real life. The thickness of the thin plate cannot be completely attenuated to zero, and there will always be a cut of a certain thickness, but the cut of a small thickness can also greatly increase the reflection coefficient at the edge, which seriously affects Zero reflection effect. In 2005, V. V. Krylov proposed that by laying appropriate damping materials on the edges of non-ideal wedge structures, the reflection coefficient increase caused by the truncation at the edges can be well reduced, making the acoustic black hole effect change from pure theoretical analysis to practically applicable [6], so acoustic black holes have attracted wide attention.

In order to explain the basic principle of the acoustic black hole phenomenon, we consider the problem of plane bending waves propagating along free wedge edges of arbitrary shapes. In this way, the propagation of bending waves in a wedge can be described by geometric acoustic approximation. The slender wedge can be regarded as a flat plate with variable local thickness. The approximate starting point is a two-dimensional equation for the bending motion of a thin plate in a vacuum, where the local thickness of the thin plate changes along the direction [7]:

$$
\begin{aligned}
& \frac{\partial^{2}}{\partial x^{2}}\left[D(x)\left(\frac{\partial^{2} w}{\partial x^{2}}+\sigma \frac{\partial^{2} w}{\partial y^{2}}\right)\right]+2(1-\sigma) \frac{\partial^{2}}{\partial x \partial y}\left[D(x) \frac{\partial^{2} w}{\partial x y}\right] \\
& +\frac{\partial^{2}}{\partial y^{2}}\left[D(x)\left(\frac{\partial^{2} w}{\partial y^{2}}+\sigma \frac{\partial^{2} w}{\partial x^{2}}\right)\right]-\omega^{2} \rho h(x) w=0
\end{aligned}
$$


Where $w$ is the normal phase displacement of the plate, $D(x)=E h^{3}(x) / 12\left(1-\sigma^{2}\right)=\left(\rho c_{p}^{2} / 12\right) h^{3}(x)$ is the local bending stiffness, $E$ and $\sigma$ are Young's modulus and Poisson's ratio, $\rho$ is Mass density, $\quad c_{p}=2 c_{t}\left(1-c_{t}^{2} / c_{l}^{2}\right)^{1 / 2}$ is phase velocity, $c_{l}, \quad c_{t}$ are $\mathrm{P}$ - wave and $\mathrm{S}$ - wave velocities for flat materials, $\omega=2 \pi f$ is Angular frequency. The solution of Equation 1 can be obtained using geometric acoustic approximation, Plate phase $\operatorname{shift}_{w(x)}$ could be express as:

$$
w=A(x) e^{i k_{p} S(x, y)}
$$

$A(x)$ and $S(x, y)=S^{\prime}(x)+\left(\beta / k_{p}\right) y$ are the slowly changing amplitude and plane wave path function, $\beta$ is projection of wave vector in $y$-axis direction, In the case of normal incidence, $\beta=0$, $k_{p}=\omega / c$ is the wave number of the p-wave of the thin plate. Bring formula 2 into formula 1 . In order for the equation to be true, both the real and imaginary parts of the resulting expression need to be zero. Set the real part to zero and keep the main term, Omitting the higher-order derivative terms of $A(x)$ and $S(x)$, we can derive the curved wave path function equation:

$$
|\nabla S(x, y)|^{4}=k^{4}(x) / k_{p}^{4}=n^{4}(x)
$$

$k(x)=12^{1 / 4} k_{p}^{1 / 2} h(x)^{-1 / 2}$ is the local wave number of the bending wave in the thickness-varying plate, $k_{p}=\omega / c_{p}, n(x)$ is the corresponding refractive index。

The solution of Equation 3 corresponding to the forward propagation along the axis is:

$$
S^{\prime}(x)=\left(1 / k_{p}\right) \int\left[k^{2}(x)-\beta^{2}\right]^{1 / 2} d x
$$

The condition for deriving the above results is that the propagation of bending waves in the black hole results meets the basic assumptions of geometric acoustics:

$$
\left|\frac{1}{k^{2}} \frac{d k}{d x}\right| \square 1
$$

Regardless of the type of wave equation, formula 5 is the most general applicable condition for the geometric acoustic approximation of waves with different physical properties. Its physical meaning is that the change in wave number is small enough within a distance equivalent to a wavelength. In addition to the local area of the ideal black hole edge, the conditions of Eq. 5 are easily satisfied.

\section{Finite element simulation}

First, a thin plate with a single ideal acoustic black hole is taken as the research object. A rectangular thin plate with a length of $60 \mathrm{~cm}$, a width of $40 \mathrm{~cm}$, and a thickness of $0.5 \mathrm{~cm}$ is established. The material parameters are shown in Table 1. Create a perfect acoustic black hole with a radius of $9 \mathrm{~cm}$ and a thickness satisfying the power law $y=50 / 81 x^{2}$ in the center of the plate. Apply a force of $F=-100 \sin (10000 t)$ on the right side. It performs time domain simulation.

Table 1.

MATERIAL PARAMETERS OF THE THIN PLATE

\begin{tabular}{|c|c|c|}
\hline Name & Value & Unit \\
\hline Density & 7850 & $\mathrm{~kg} / \mathrm{m}^{3}$ \\
\hline Young's modulus & $200 \mathrm{e} 9$ & $\mathrm{~Pa}$ \\
\hline Poisson's ratio & 0.30 & 1 \\
\hline Loss factor & 0.004 & 1 \\
\hline
\end{tabular}




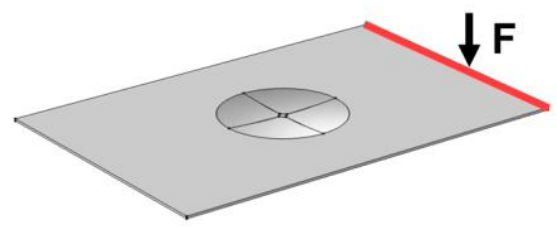

Figure 1. Thin plate with a single ideal acoustic black hole

Create a rectangular thin plate with a length of $60 \mathrm{~cm}$, a width of $40 \mathrm{~cm}$, and a thickness of 0.52 $\mathrm{cm}$. Create four acoustic black holes with a radius of $9 \mathrm{~cm}$ and satisfy the power law $y=25 / 32 \times(x-1)$ $\wedge 2+0.02$. There is a truncation at the center of the acoustic black hole with a truncation radius of $1 \mathrm{~cm}$ and a truncation thickness of $0.02 \mathrm{~cm}$. A rubber damping layer with a radius of $3.5 \mathrm{~cm}$ and a thickness of $0.2 \mathrm{~cm}$ is laid on the acoustic black hole. The material parameters are shown in Table 2.A vertical downward force of $100 \mathrm{~N}$ is applied to the right side for frequency domain analysis. The response pick points are $(0,0,0.52),(0,10,0.52),(0,-10,0.52),(-25,10,0.52),(-25,-10,0.52)$.

Table 2

MATERIAL PARAMETERS OF THE RUBBER DAMPING LAYER

\begin{tabular}{|c|c|c|}
\hline Name & Value & Unit \\
\hline Density & 1780 & $\mathrm{~kg} / \mathrm{m}^{3}$ \\
\hline Young's modulus & $0.1 \mathrm{e} 6$ & $\mathrm{~Pa}$ \\
\hline Poisson's ratio & 0.45 & 1 \\
\hline Loss factor & 0.28 & 1 \\
\hline
\end{tabular}

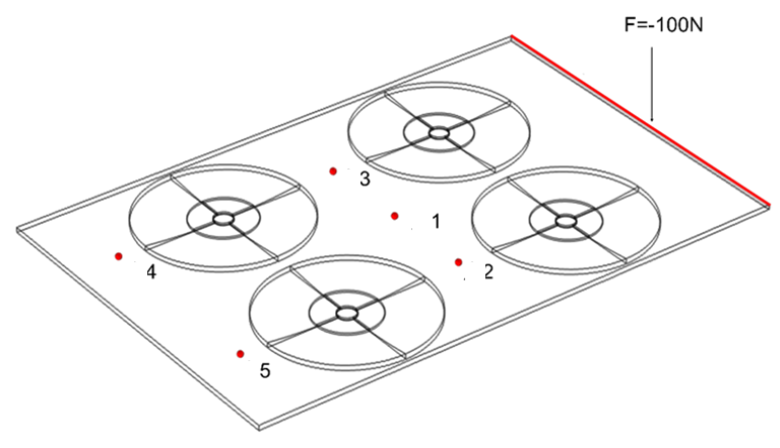

a

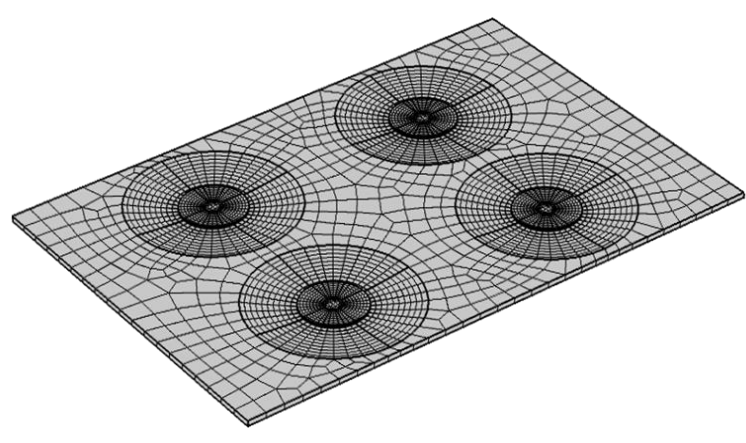

b

Figure 2. Schematic diagram of acoustic black hole thin plate model a Acoustic black hole plate model; $b$ Acoustic black hole grid model

\section{Analysis of simulation calculation results}

Velocity maps are retrieved from the time domain simulation calculation results for comparison and analysis. The cloud maps of velocity at different times are shown in Figure 3.

It can be seen from Fig. 3 that the vibration is transmitted from the right excitation end to the left. When passing through an ideal acoustic black hole, the vibration speed is concentrated toward the center of the black hole, thereby generating a wave blocking effect.

Integrate the density and elastic strain energy density separately in comsol to obtain the mass of the acoustic black hole portion and the entire thin plate and the elastic strain energy of the acoustic black hole portion and the entire thin plate at each moment, and obtain the acoustic black hole portion at each moment. The ratio of mass and elastic strain energy to the entire thin plate. The obtained mass of the acoustic black hole accounts for $5,6 \%$ of the entire thin plate. 


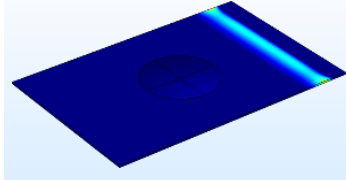

(a) $\mathrm{t}=0.0001 \mathrm{~s}$

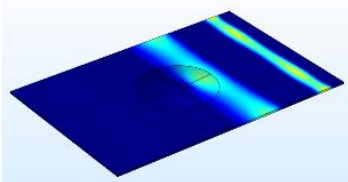

(e) $\mathrm{t}=0.0009 \mathrm{~s}$

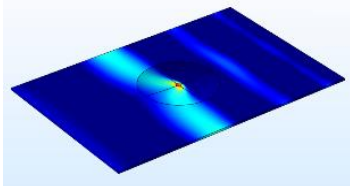

(i) $\mathrm{t}=0.0017 \mathrm{~s}$

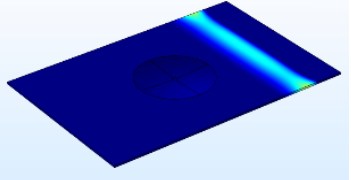

(b) $\mathrm{t}=0.0003 \mathrm{~s}$

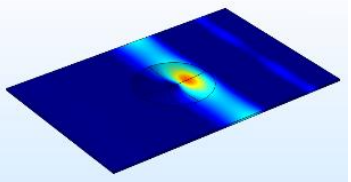

(f) $\mathrm{t}=0.0011 \mathrm{~s}$

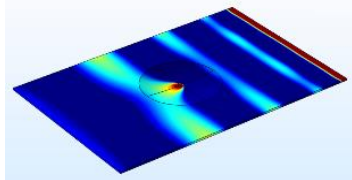

(j) $\mathrm{t}=0.0019 \mathrm{~s}$

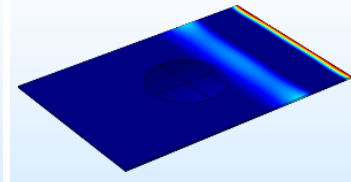

(c) $\mathrm{t}=0.0005 \mathrm{~s}$

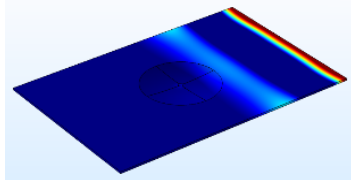

(d) $\mathrm{t}=0.0007 \mathrm{~s}$

Figure 3. Cloud maps of velocity at different moments

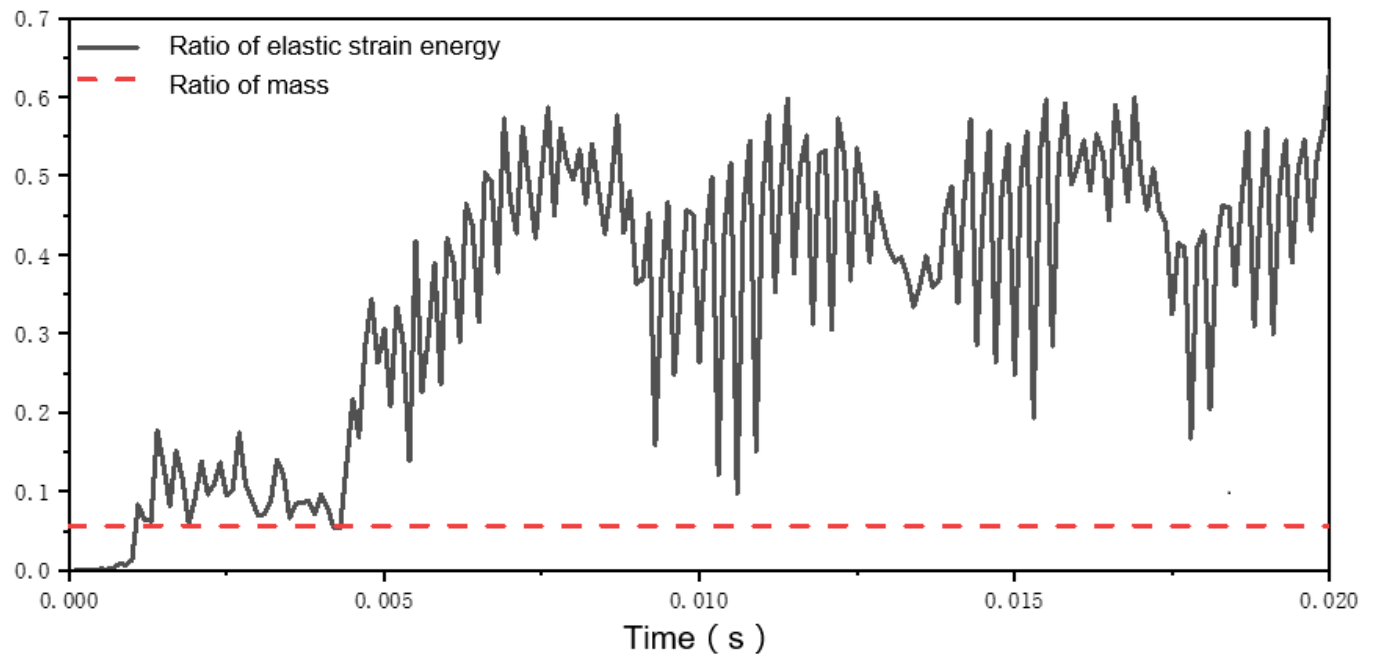

Figure 4. The proportion of acoustic black hole mass and elastic strain energy to the entire thin plate

It can be seen from Figure 4 that with the increase of time, especially when the time is greater than $0.005 \mathrm{~s}$, the proportion of elastic strain energy changes periodically. This is because when the time exceeds $0.005 \mathrm{~s}$, the vibration starts to propagate to the acoustic black hole portion. In the thin plate, the mass of the acoustic black hole area only accounts for $5.6 \%$ of the total mass, and the maximum ratio of elastic strain energy can exceed 50\%, and the wave blocking effect is obvious.

A frequency domain analysis of a thin plate containing 4 acoustic black holes is shown in Figure 5-9. Take the mechanical energy flow diagram in comsol, and the result is shown in Figure 10. 


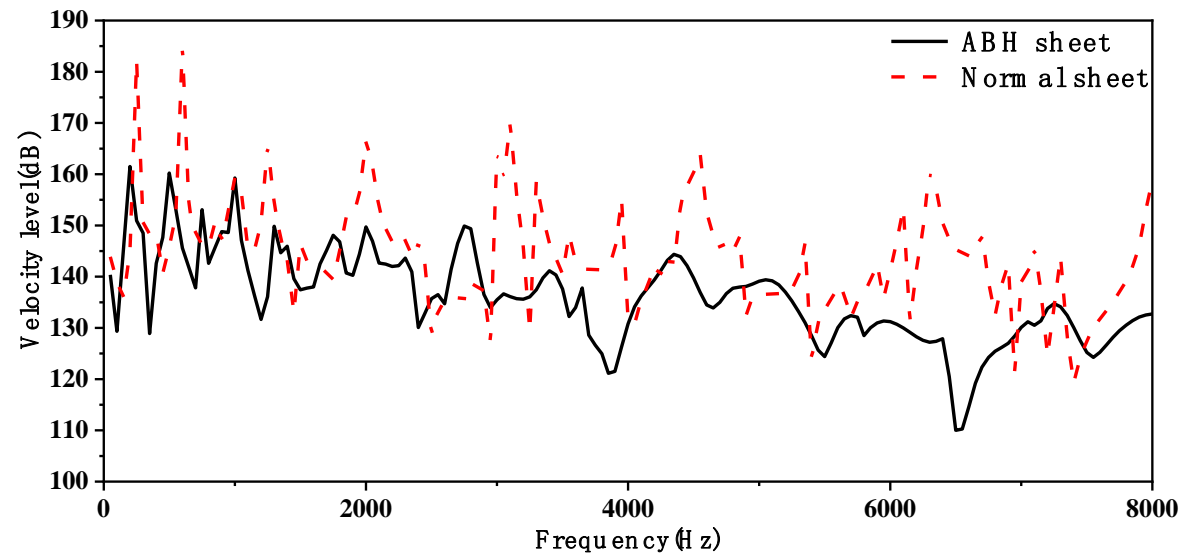

Figure 5. Comparison of velocity levels at response point 1 of each plate

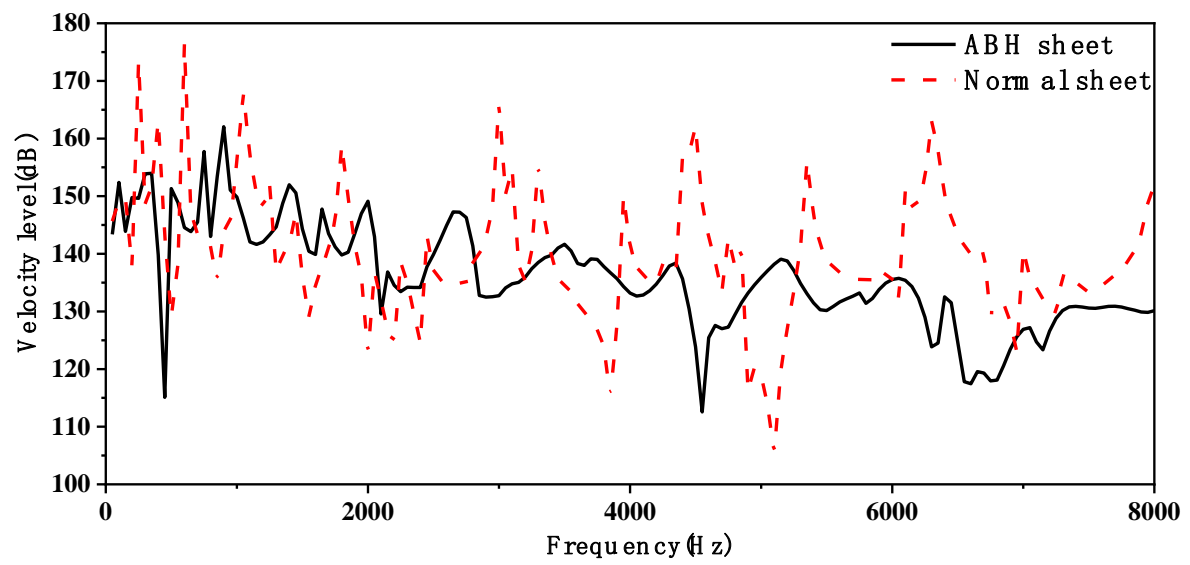

Figure 6. Comparison of velocity levels at response point 2 of each plate

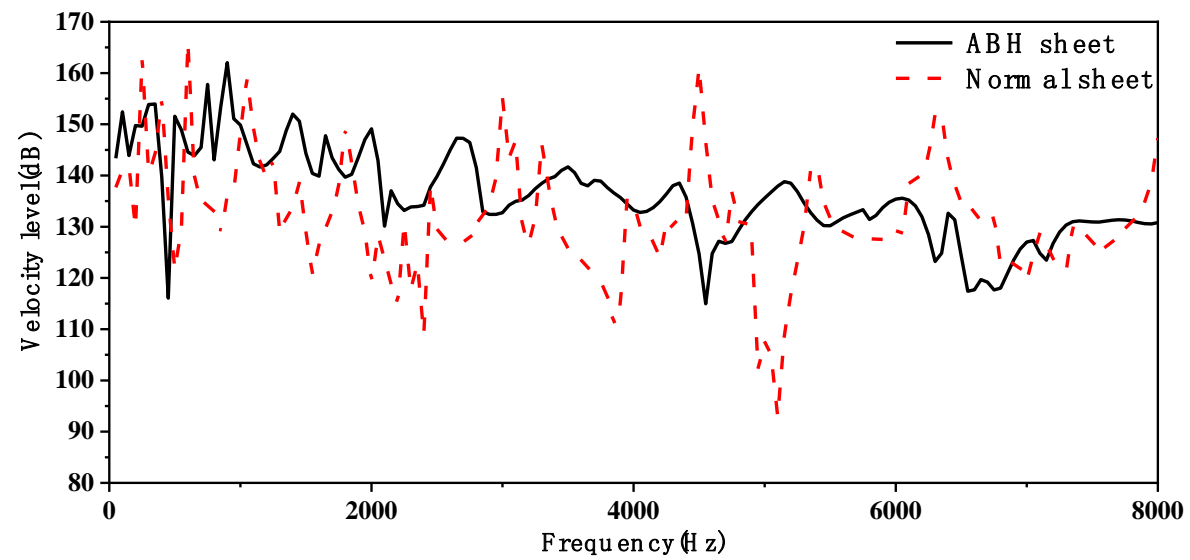

Figure 7. Comparison of velocity levels at response point 3 of each plate 


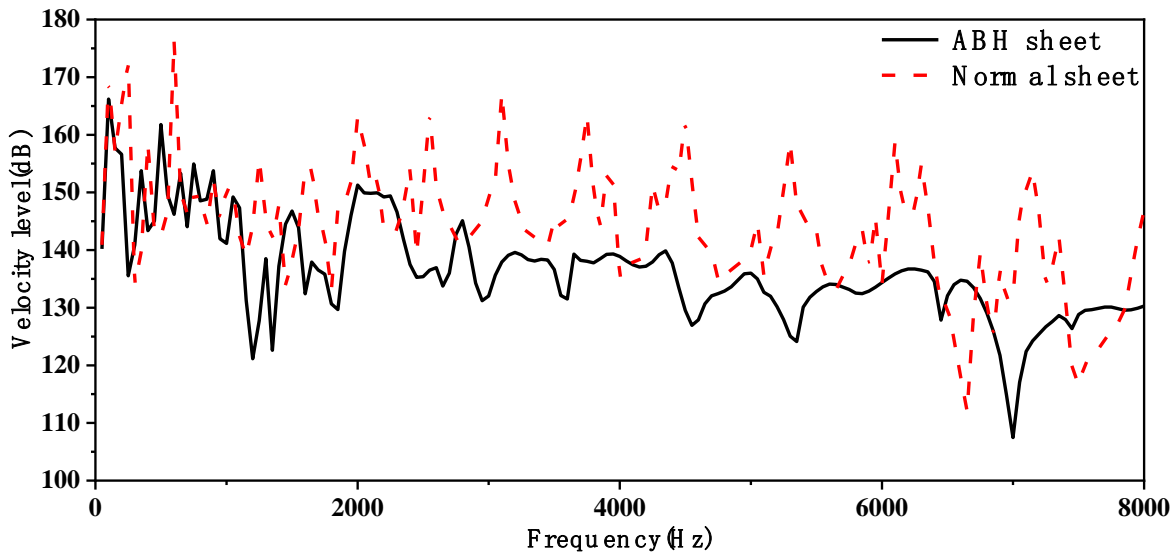

Figure 8. Comparison of velocity levels at response point 4 of each plate

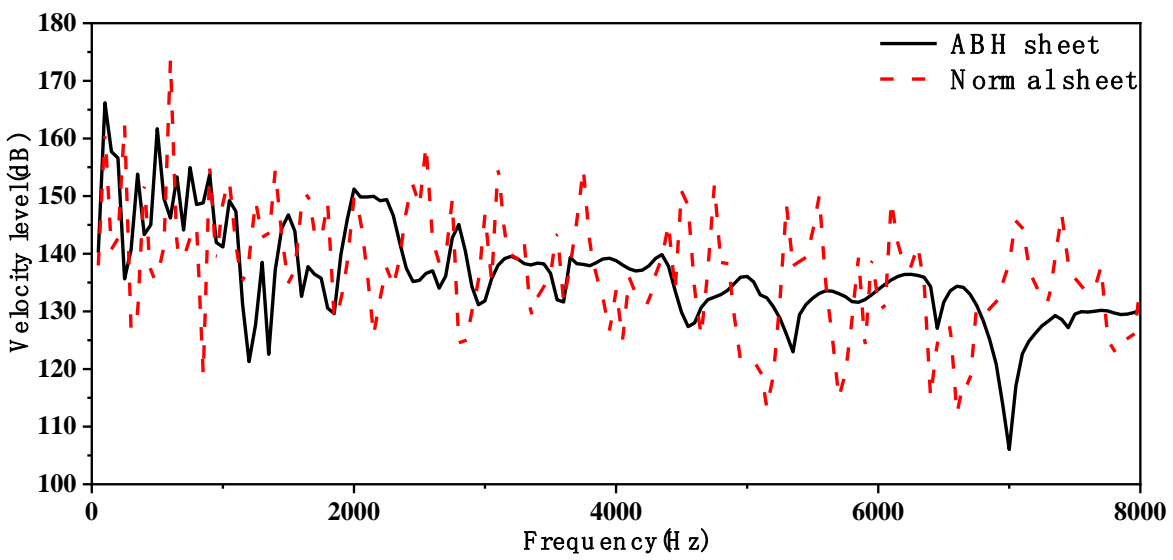

Figure 9. Comparison of velocity levels at response point 5 of each plate

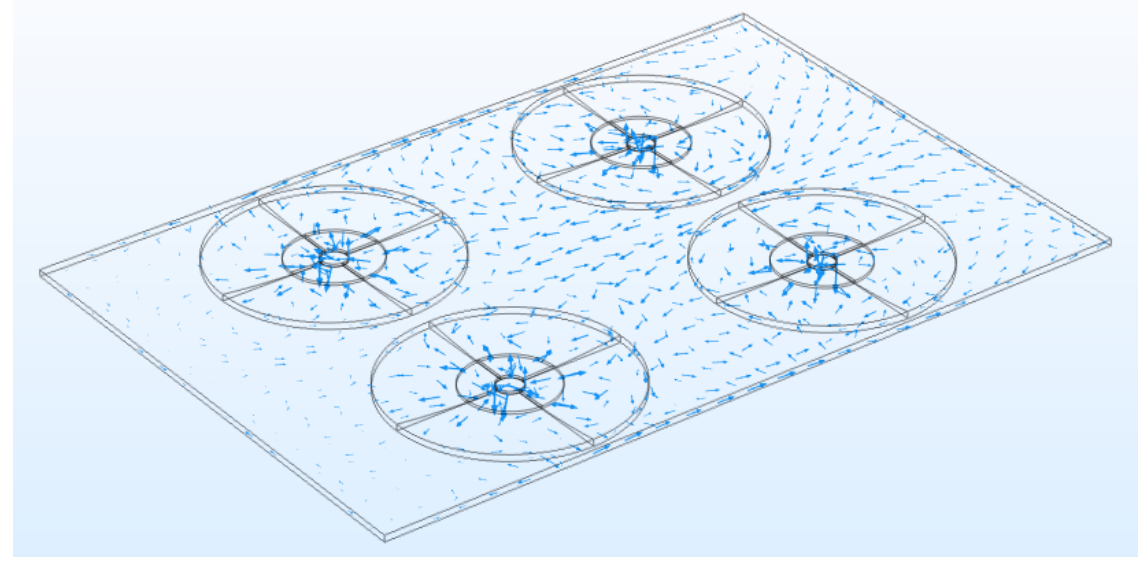

Figure 10. Mechanical energy flow

Except for the non-acoustic black hole, the control group had the same parameters as the acoustic black hole panel. Through comparison, it is found that the performance of the acoustic black hole panel with a damping layer is generally better than that of ordinary panels, and the peak value of vibration is significantly less than that of ordinary panels. After passing through the two-stage acoustic black hole blocking wave at point 4 , its vibration speed level is basically lower than that of the ordinary panel in the entire frequency range. It is found that the non-ideal acoustic black hole with damping material also 
has good wave blocking characteristics and energy accumulation effect by using the mechanical energy flow cloud diagram calculated by finite element simulation.

\section{Conclusion}

Time-domain simulation of a thin plate with a single perfect acoustic black hole and frequencydomain simulation of a thin plate with 4 imperfect acoustic black holes are done. Concluded as follow:

The acoustic black hole structure has a good wave blocking effect and energy concentration effect, and can use less space and mass to concentrate more vibration energy. During the vibration process, the concentrated elastic strain energy of the acoustic black hole area on a single ideal acoustic black hole plate can reach $55 \%$ of the entire plate at the highest moment.

The 4-acoustic black hole thin plate structure proposed in this paper has good vibration damping effect. At individual points, it has a good damping effect even at low frequencies, and it is more obvious at high frequencies. At some points, the vibration reduction effect can reach more than $30 \mathrm{~dB}$ at high frequencies.

In general, the acoustic black hole structure has good wave blocking performance, energy concentration performance and vibration damping performance. It is light in weight, simple in structure, and not difficult to process, and has a good prospect in engineering applications.

\section{Reference}

1. Pekeris, C. L. (1946). Theory of propagation of sound in a half-space of variable sound velocity under conditions of formation of a shadow zone. The Journal of the Acoustical Society of America, 18(2), 295-315. https://doi.org/10.1121/1.1916366

2. Mironov, M. A. (1988). Propagation of a flexural wave in a plate whose thickness decreases smoothly to zero in a finite interval. Soviet Physics Acoustics-USSR, 34(3), 318-319.

3. Krylov, V. V. (1989). Conditions for validity of the geometrical-acoustics approximation in application to waves in an acute-angle solid wedge. Soviet Phys.-Acoust, 35(2), 176-180.

4. Krylov, V. V. (2001). A new type of vibration damper based on flexural wave propagation in laminated wedges of power-law profile. The Journal of the Acoustical Society of America, 110(5), 2654-2654. https://doi.org/10.1121/1.4777028

5. Krylov, V. V. (2004). New type of vibration dampers utilising the effect of acoustic'black holes'. Acta Acustica united with Acustica, 90(5), 830-837.

6. Krylov, V. V., \& Winward, E. (2005). Experimental evidence of the acoustic black hole effect for flexural waves in tapered plates. https://doi.org/10.1016/j.jsv.2006.07.035

7. Krylov, V. V. (2014). Acoustic black holes: Recent developments in the theory and applications. IEEE transactions on ultrasonics, ferroelectrics, and frequency control, 61(8), 12961306.

\section{Список литературы:}

1. Pekeris C. L. Theory of propagation of sound in a half-space of variable sound velocity under conditions of formation of a shadow zone // The Journal of the Acoustical Society of America. 1946. Vol. 18. №2. P. 295-315. https://doi.org/10.1121/1.1916366

2. Mironov M. A. Propagation of a flexural wave in a plate whose thickness decreases smoothly to zero in a finite interval // Soviet Physics Acoustics-USSR. 1988. Vol. 34. №3. P. 318-319.

3. Krylov V. V. Conditions for validity of the geometrical-acoustics approximation in application to waves in an acute-angle solid wedge // Soviet Phys.-Acoust. 1989. Vol. 35. №2. P. 176-180. 
4. Krylov V. V. A new type of vibration damper based on flexural wave propagation in laminated wedges of power-law profile // The Journal of the Acoustical Society of America. 2001. Vol. 110. №5. P. 2654-2654. https://doi.org/10.1121/1.4777028

5. Krylov V. V. New type of vibration dampers utilising the effect of acoustic'black holes' // Acta Acustica united with Acustica. 2004. Vol. 90. №5. P. 830-837.

6. Krylov V. V., Winward E. Experimental evidence of the acoustic black hole effect for flexural waves in tapered plates. 2005. https://doi.org/10.1016/j.jsv.2006.07.035

7. Krylov V. V. Acoustic black holes: Recent developments in the theory and applications // IEEE transactions on ultrasonics, ferroelectrics, and frequency control. 2014. Vol. 61. №8. P. 1296-1306.

Работа поступила

в редакцию 02.03.2020 г.
Принята к публикациии

09.03.2020 z.

Ссылка для циитирования:

Liu Z., Zhou Y., Golyanin A. Simulation Study on the Blocking Effect and Vibration Reduction Characteristics of Acoustic Black Hole in Thin Plate // Бюллетень науки и практики. 2020. T. 6. №4. C. 223-231. https://doi.org/10.33619/2414-2948/53/26

Cite as (APA):

Liu, Z., Zhou, Y., \& Golyanin, A. (2020). Simulation Study on the Blocking Effect and Vibration Reduction Characteristics of Acoustic Black Hole in Thin Plate. Bulletin of Science and Practice, 6(4), 223-231. https://doi.org/10.33619/2414-2948/53/26 